\title{
Immunohistochemical Subtypes of Breast Cancer: Correlation with Clinicopathological and Radiological Factors
}

\author{
Yu-Mee Sohn, ${ }^{1,}$ Kyunghwa Han, ${ }^{2}$ and Mirinae $\mathrm{Seo}^{1}$ \\ ${ }^{1}$ Department of Radiology, Kyung Hee University Hospital, College of Medicine, Kyung Hee University, Seoul, South Korea \\ ${ }^{2}$ Department of Radiology, Yonsei Biomedical Research Institute, Research Institute of Radiological Science, Seoul, South Korea \\ "Corresponding author: Yu-Mee Sohn, Department of Radiology, Kyung Hee University Hospital, College of Medicine, Kyung Hee University, Seoul, South Korea. Tel: \\ +82-29588625, Fax: +82-29680787, E-mail: sonyumee@naver.com
}

Received 2015 July 10; Revised 2015 November 17; Accepted 2016 February 15.

\begin{abstract}
Background: The relationship between biomarkers and imaging features is important because imaging findings can predict molecular features.

Objectives: To investigate the relationship between clinicopathologic and radiologic factors and the immunohistochemical (IHC) profiles associated with breast cancer.

Patients and Methods: From December 2004 to September 2013, 200 patients (mean age, 56 years; range, 29 - 82 years) were diagnosed with breast cancer and underwent surgery at our institution. Their medical records were reviewed to determine age, symptom presence, mammographic findings (including mass, asymmetry, microcalcifications, or negativity), sonographic Breast Imaging-Reporting and Data System (BI-RADS) category, pathologic type of cancer (invasive ductal, mucinous, medullary, or papillary carcinoma), histologic grade, T-stage, and IHC subtypes. Based on the IHC profiles, tumor subtypes were classified as luminal A, luminal B, human epidermal growth factor receptor 2 (HER2) enriched, or triple-negative (TN) cancers. Using univariate and multivariate logistic regression analyses, we looked for correlations between four IHC subtypes and two IHC subtypes (TN and non-triple negative [non-TN]) and clinicopathologic and radiologic factors, respectively.

Results: Based on our univariate analyses with the four subtypes, the TN subtype showed a higher incidence of masses on mammography compared to the other subtypes $(\mathrm{P}=0.037)$, and the TN subtype also tended to have the highest histologic grade among the subtypes $(\mathrm{P}<0.001)$. With regard to the two IHC subtypes, the TN subtype had a significant association with medullary cancer $(\mathrm{P}=0.021)$, higher histologic grade (grade $3 ; \mathrm{P}<0.001$ ), and higher $\mathrm{T}$ stage $(\mathrm{T} 2 ; \mathrm{P}=0.027)$ compared to the non-TN subtypes. In a multivariate logistic regression analysis of the clinicoradiologic factors compared to luminal A, the HER2 subtype had a significant association with BI-RADS category $4 \mathrm{~b}$ (odds ratio [OR], 9.005; 95\% confidence interval [CI], $1.414-57.348 ; \mathrm{P}=0.020$ ) and borderline significance with category $4 \mathrm{C}(\mathrm{OR}, 4.669 ; 95 \% \mathrm{CI}, 0.970-22.468 ; \mathrm{P}=0.055)$. In a multivariate logistic regression analysis of the clinicoradiologic factors associated with the non-TN subtypes, the TN subtype was significantly correlated with medullary carcinoma (OR, 7.092; 95\% CI, 1.149 - 43.772; $\mathrm{P}=0.035)$.

Conclusion: These results suggest that patients with the TN subtypes are more likely to have higher-histologic-grade tumors and medullary cancer. The HER2 subtype was typically associated with a higher BI-RADS category.
\end{abstract}

Keywords: Immunohistochemical (IHC) Profile, Breast Cancer, Mammography, Ultrasound

\section{Background}

Breast cancer is a highly heterogeneous disease with a variety of morphologic and clinical manifestations, which results in a range of responses to treatment (1-3). Recently, targeted therapies based on the genetic, hormonal, or immunohistochemical (IHC) subtypes of breast cancer have been used. Therefore, the examination of IHC subtypes using breast cancer tissue is actively performed. IHC determinations of estrogen receptor (ER), progesterone receptor (PR), human epidermal growth factor receptor 2 (HER2), and Ki67 statuses are used to define these sub- types (4-6). With DNA microarray-expression profiling techniques, we can use a hierarchical clustering method to identify four distinct molecular subtypes: 1) luminal A (ER- and/or PR-positive, HER2-negative); 2) luminal B (ERand/or PR-positive, HER2-positive or Ki67 > 14\%); 3) HER2enriched (HER2 amplified, ER- and PR-negative); and 4) triple-negative (TN) (ER-, PR-, and HER2-negative) subtypes. Prognosis and survival are different according to these subtypes (6). Luminal tumors are associated with the most favorable prognoses, while HER2-overexpressing and triplenegative tumors are associated with the worst prognosis $(2,7)$. 
Due to these different prognoses and treatment strategies, prior knowledge of molecular subtypes is essential to managing breast cancer patients. Thus, the relationship between biomarkers and imaging features is important because imaging findings can predict molecular features (8). The imaging features most commonly associated with triple-negative breast cancer (TNBC) are generally morphologically benign, and several reports show a correlation between clinical, pathological, and radiologic features of these molecular subtypes (9-13). However, comparisons between TNBC and non-TNBC have not been well described.

\section{Objectives}

The purpose of our study was to evaluate the four IHC subtypes and to compare TNBC and non-TNBC with regard to clinicopathologic and radiologic features.

\section{Patients and Methods}

This retrospective study was approved by the Kyung Hee University hospital's institutional review board, and informed consent was waived. Written informed consent for biopsy or surgery was obtained from all patients before undergoing any procedures.

\subsection{Patients}

From December 2004 to September 2013, 403 patients were initially diagnosed with primary breast cancer at our institution. Among them, we excluded patients who: 1) were transferred to other hospitals according to their preference ( $n=103) ; 2$ ) underwent neoadjuvant chemotherapy $(\mathrm{n}=56) ; 3$ ) were without available preoperative mammography or ultrasound (US) $(n=29)$; or 4$)$ were without sufficient clinicopathological data $(n=15)$. Finally, 200 patients with 200 cancers were enrolled in current study.

\subsection{Imaging Analyses}

Mammograms were obtained with standard craniocaudal (CC) and mediolateral oblique (MLO) views for each breast using dedicated full-field digital mammography (Senographe DS; GE Healthcare, Milwaukee, WI, USA). One board-certified radiologist(S.Y.M.) with eight years of experience in breast imaging reviewed all mammograms and recorded the status (mass, asymmetry, microcalcifications with or without mass, negativity), and also conducted a final Breast Imaging-Reporting and Data System (BI-RADS) assessment based on the mammographic findings (14).

Breast US examination, including the axillary area, was performed with a high-resolution sonographic unit using 5 - 10-MHz or 5 - 12-MHz linear-array transducers (ATL HDI
5000, Philips healthcare-advanced technology laboratories, Bothell, WA, USA; Logic 9, GE Healthcare, Milwaukee, WI, USA) operated by full-time board-certified radiologists with seven years of experience in breast imaging. Lesion size was measured in two different orthogonal views, and the final assessment of US images was performed according to BI-RADS (15).

\subsection{Clinicopathological Features}

We reviewed the patients' medical records for clinicopathologic findings, including age, mean size of primary breast cancer, presence of symptoms, T-stage, ER status, PR status, HER2 status, and histologic grade. Tumor size was determined based on the pathology report, and was categorized according to the guidelines of the American joint committee on cancer, $7^{\text {th }}$ Edition (16).

ER, PR, and HER2 expression in primary tumors were analyzed by IHC staining of formalin-fixed, paraffinembedded whole sections of resected breast cancer specimens. Primary antibodies for ER (1: 200, 6F11, Novocastra, Newcastle, UK), PR (1: 200, PGR, Novocastra), and HER2 (1: 500, A0485, DAKO, Denmark) were used. ER and PR were considered positive if tumors had more than $10 \%$ nuclear-stained cells. HER2 staining was scored on a scale of 0 to $3+$, according to the HercepTest guidelines (17); HER2 was considered positive when graded as $2+$, while 0 to $1+$ were negative. Histologic grade was classified into two groups, non-high-grade and high-grade, according to the Scarff-Bloom-Richardson grade system (18). According to hormonal status, each case was designated into one of four distinct molecular subtypes: luminal A, luminal B, HER2-enriched, and TN.

\subsection{Statistical Analyses}

Clinicopathological features and radiological findings were compared statistically between the four subtypes and also between two subtypes (TN and non-TN) using the t-test for continuous variables and Chi-Square or Fisher's exact test for non-continuous variables.

A multivariate logistic analysis was performed to identify the variables that were independently associated with the different cancer subtypes. Data were analyzed using SAS, version 9.2 (SAS Institute, Cary, NC, USA). Differences were considered statistically significant at $\mathrm{P}<0.05$.

\section{Results}

The mean age of the patients in our study was 56 years (range, 29 - 82 years). The mean size of the primary breast cancers was $20.6 \mathrm{~mm}$ (range, $4-70 \mathrm{~mm}$ ). One hundred twenty-two patients had symptoms, including palpability 

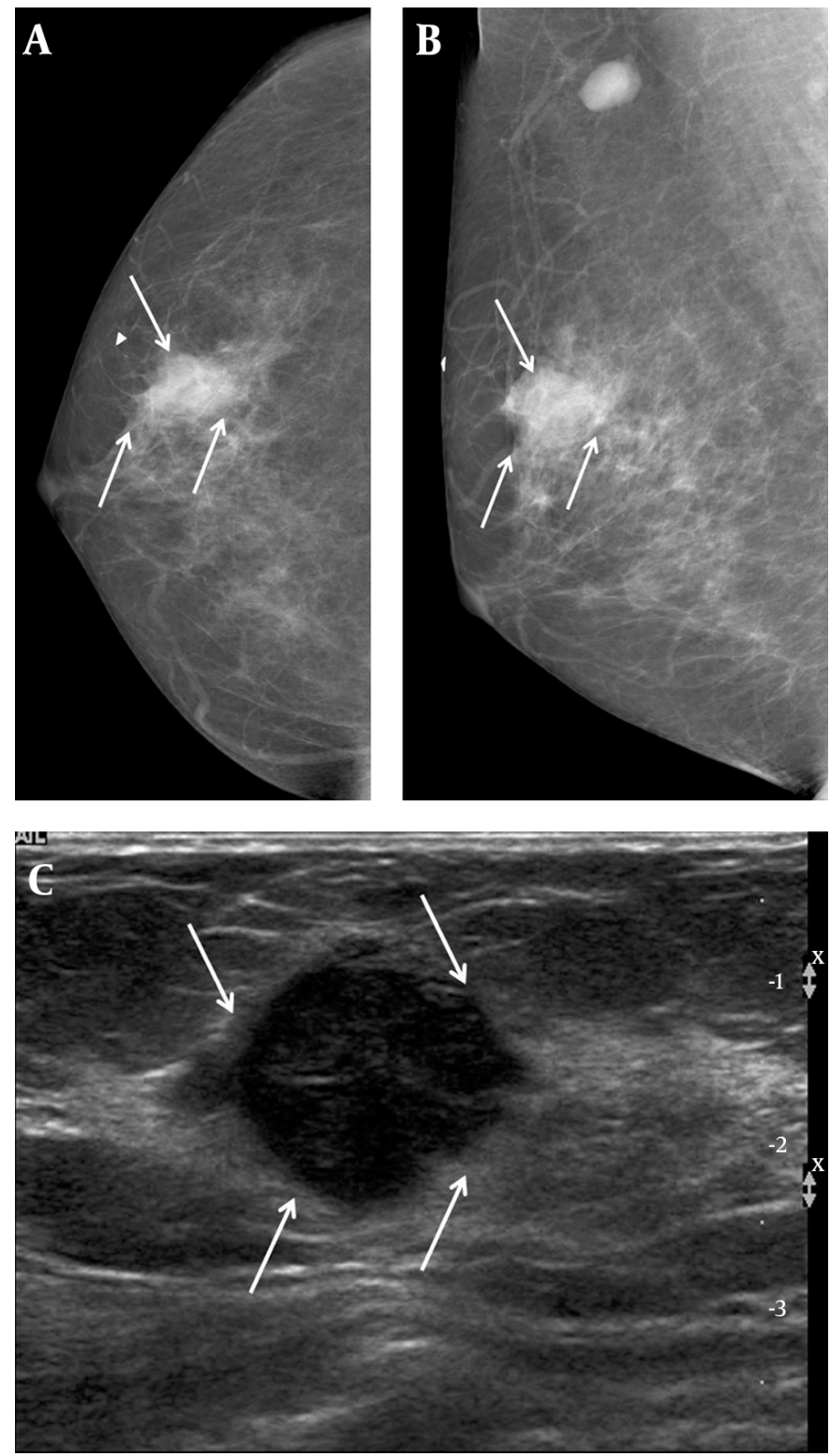

Figure 1. A 57-year-old woman complained of a palpable mass in her right breast. A, Right craniocaudal and B, Mediolateral oblique views on mammography showed an indistinct margin, with a round mass and without calcifications on the BB marker site in the right upper outer area (arrows). An enlarged lymph node is also seen in the right axillary area. C, Transverse ultrasound revealed a hypoechoic mass that was microlobulated with a round shape (arrows), and which we categorized as BI-RADS category 4b. US-CNB was performed, and the case was confirmed to be medullary carcinoma. The patient underwent breast-conservation surgery and was subsequently labeled as a histologic grade 3, TNBC. TNBC: Triple-negative breast cancer; US-CNB: Ultrasound-guided core needle biopsy

( $\mathrm{n}=112)$, pain $(\mathrm{n}=3)$, nipple discharge $(\mathrm{n}=5)$, and axillary mass $(n=2)$. IHC profiles revealed that 77 patients $(38.5 \%)$ had luminal A type tumors, 54 (27.0\%) had luminal B type tumors, 35 (17.5\%) had HER2-enriched tumors, and 34 (17.0 $\%$ ) had TN tumors.

Among the four IHC subtypes, TN had the highest incidence of mass presence $(\mathrm{P}=0.037)$ based on mammo- graphic findings (Table 1). The TN subtype also had the highest histologic grade among the four subtypes $(\mathrm{P}<$ 0.001). The HER2-enriched and TN subtypes were significantly associated with T2 stage, compared to the luminal $A$ and luminal B subtypes $(\mathrm{P}<0.001)$. Patient age, presence of symptoms, sonographic BI-RADS category, and cancer type were not significantly associated with any of the 

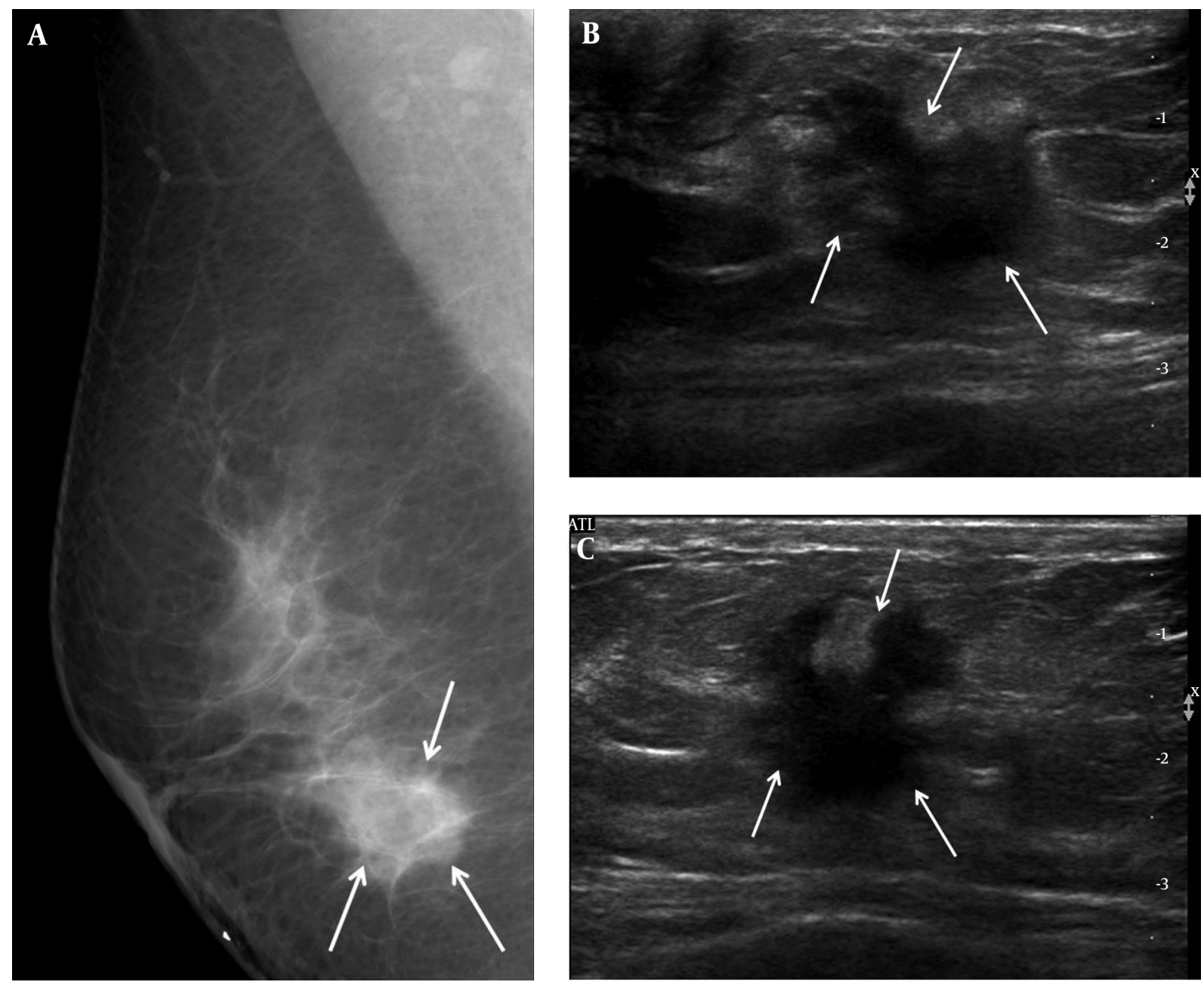

Figure 2. A 46-year-old woman complained of a palpable mass in her right breast. A, Right mediolateral oblique view on mammography showed an ill-defined marginated mass (arrows) on the BB marker site in the right lower area. B, Transverse and C, Longitudinal ultrasound revealed a hypoechoic mass with an irregular shape and a spiculated margin (arrows); we categorized it as BI-RADS category 5. US-CNB was performed, and confirmed invasive ductal carcinoma. The patient underwent modified radical mastectomy, after which the mass was labeled histologic grade 2, luminal A breast cancer. US-CNB: Ultrasound-guided core needle biopsy

four subtypes.

In the analysis of the two IHC subtypes, TN had a significant association with medullary cancer $(\mathrm{P}=0.021)$, higher histologic grade (grade 3; $\mathrm{P}<0.001$ ) and higher T stage (T2; $\mathrm{P}=0.027)$ compared to the non-TN subtype. The TN subtype showed a higher incidence of masses than the nonTN subtype on mammography, with no significant difference. There were also no significant associations among these two subtypes and age, the presence of symptoms, or sonographic BI-RADS category (Table 2 ).

We ran multivariate logistic regression analyses that compared clinicoradiologic factors to luminal A subtypes after adjustment of histologic grade, and found that the HER2 subtype had a significant association with BI-RADS category $4 \mathrm{~b}$ (odds ratio $[\mathrm{OR}]=9.005 ; 95 \%$ confidence inter$\operatorname{val}[\mathrm{CI}]=1.414-57.348 ; \mathrm{P}=0.020)$ and was weakly associated with category $4 \mathrm{c}(\mathrm{OR}=4.669 ; 95 \% \mathrm{CI}=0.970-22.468 ; \mathrm{P}=$ $0.055)$. There was also a significant difference in risk for $\mathrm{T} 2$ and $\mathrm{T} 3$ staging $(\mathrm{OR}=3.173 ; 95 \% \mathrm{CI}=1.248-8.066 ; \mathrm{P}=0.015$ and $\mathrm{OR}=6.552 ; 95 \% \mathrm{CI}=1.252-34.296 ; \mathrm{P}=0.026$, respectively) (Table 3 ).

Our multivariate logistic regression analysis comparing clinicoradiologic factors to non-TN subtypes after adjustment of histologic grade found that the TN subtype was significantly correlated with medullary carcinoma $(\mathrm{OR}=7.092 ; 95 \% \mathrm{CI}=1.149-43.772 ; \mathrm{P}=0.035)$ and $\mathrm{T} 3$ stage $(\mathrm{OR}=23.652 ; 95 \% \mathrm{CI}=14.211-132.830 ; \mathrm{P}=0.003)$ (Table 4). 
Table 1. Clinicoradiologic and Pathologic Features Stratified by Four IHC Subtypes ${ }^{\mathrm{a}}$

\begin{tabular}{|c|c|c|c|c|c|}
\hline Variable & Luminal A $(n=77)$ & Luminal B $(n=54)$ & HER2 + $(n=35)$ & $\mathbf{T N}(\mathbf{n}=\mathbf{3 4})$ & P Value \\
\hline Patient age (mean $\pm S D$, range) & $57.4 \pm 11.3(29-82)$ & $55.3 \pm 10.3(34-78)$ & $60.9 \pm 9.0(45-78)$ & $54.9 \pm 11.3(33-80)$ & 0.064 \\
\hline Symptoms & & & & & 0.263 \\
\hline Yes & $49(63.6)$ & $27(50)$ & $24(68.6)$ & $22(64.7)$ & \\
\hline No & $28(36.4)$ & $27(50)$ & $11(31.4)$ & $12(35.3)$ & \\
\hline MMG finding & & & & & 0.037 \\
\hline Asymmetry & $11(14.3)$ & $4(7.4)$ & $4(7.4)$ & $2(5.9)$ & \\
\hline Mass & $48(62.3)$ & $34(62.9)$ & $20(57.1)$ & $25(73.5)$ & \\
\hline Microcalcification \pm mass & $11(14.3)$ & $16(29.6)$ & $11(31.4)$ & $4(11.8)$ & \\
\hline Negative & $7(9.1)$ & $0(0)$ & $0(0)$ & $3(8.8)$ & \\
\hline US BI-RADS & & & 1.0 & & 0.109 \\
\hline $4 a$ & $18(23.4)$ & $11(20.4)$ & $2(5.7)$ & $6(17.7)$ & \\
\hline $4 \mathrm{~b}$ & $8(10.4)$ & $2(3.7)$ & $7(20.0)$ & $5(14.7)$ & \\
\hline$>4 \mathrm{c}$ & $51(66.2)$ & $41(75.9)$ & $26(74.3)$ & $23(67.6)$ & \\
\hline Cancer type & & & & & 0.284 \\
\hline IDC & $70(90.9)$ & $50(92.6)$ & $34(97.1)$ & $30(88.2)$ & \\
\hline Mucinous & $5(6.5)$ & $3(5.6)$ & $1(2.9)$ & $0(0)$ & \\
\hline Medullary & $1(1.3)$ & $1(1.9)$ & $0(0)$ & $3(8.9)$ & \\
\hline Papillary & $1(1.3)$ & $0(0)$ & $0(0)$ & $1(2.9)$ & \\
\hline Histologic grade & & & & & $<0.001$ \\
\hline 1 & $28(37.3)$ & $12(23.1)$ & $3(8.6)$ & $1(3.0)$ & \\
\hline 2 & $38(50.7)$ & $30(57.7)$ & $19(54.3)$ & $6(18.2)$ & \\
\hline 3 & $9(12.0)$ & $10(19.2)$ & $13(37.1)$ & $26(78.8)$ & \\
\hline T stage & & & & & $<0.001$ \\
\hline $\mathrm{T} 1$ & $47(64.0)$ & $32(59.3)$ & $10(28.6)$ & $12(35.3)$ & \\
\hline T2 & $27(35.1)$ & $21(38.9)$ & $20(57.1)$ & $22(64.7)$ & \\
\hline T3 & $3(3.9)$ & $1(1.9)$ & $5(14.3)$ & $0(0)$ & \\
\hline
\end{tabular}

Abbreviations: BI-RADS, breast imaging reporting and data system; IDC, invasive ductal carcinoma; IHC, immunohistochemical; MMG, mammographic; SD, standard deviation; TN, triple negative; US, ultrasound.

${ }^{\mathrm{a}}$ Values are expressed as No. (\%).

\section{Discussion}

Currently, breast cancer treatment is typically adjusted according to the particular IHC characteristics of the tumor. Therefore, researchers have sought to determine how well imaging findings can reveal the molecular subtype of a tumor, which would improve the potential for preoperatively-planned treatment strategies. Several studies have explored the correlations between various imaging findings, including mammography, US, and magnetic resonance imaging (MRI), and the clinical features based on various histopathologic markers $(8,9,12,13,19-23)$.

In this study, when analyzing four different subtypes, we found that the TN subtypes were more likely to be associated with a mass on mammography than the other subtypes. This finding is consistent with other studies, despite differences between study designs (9, 11, 13, 20, 24, 25). TN subtypes are generally described as relatively well-defined noncalcified masses that mimic benign breast lesions, or sometimes as ill-defined or spiculated marginated masses or focal asymmetry $(9,11,13,20,24-29)$. In fact, the TN subtype is aggressive, rapidly proliferating, and less associated with ductal carcinoma in situ (DCIS) than other subtypes (23). Also, the TN subtype has been found to have a lower association with microcalcifications $(9,11,23,28,29)$, in accordance with our own findings. TN subtypes were also associ- 
Table 2. Clinicoradiologic and Pathologic Features, Stratified by Two IHC Subtypes ${ }^{\mathrm{a}}$

\begin{tabular}{|c|c|c|c|}
\hline IHC Subtype & Non-TN $(n=166)$ & $\mathrm{TN}(\mathbf{n}=\mathbf{3 4})$ & P Value \\
\hline Patient age (mean \pm SD, range) & $57.5 \pm 10.7(33-80)$ & $54.9 \pm 11.3(33-80)$ & 0.222 \\
\hline Symptoms & & & 0.627 \\
\hline Yes & $49(63.6)$ & $22(64.7)$ & \\
\hline No & $28(36.4)$ & $12(35.3)$ & \\
\hline MMG finding & & & 0.215 \\
\hline Asymmetry & $19(11.5)$ & $2(5.9)$ & \\
\hline Mass & $102(61.5)$ & $25(73.5)$ & \\
\hline Microcalcification \pm mass & $38(22.8)$ & $4(11.8)$ & \\
\hline Negative & $7(4.2)$ & $3(8.8)$ & \\
\hline US BI-RADS & & & 0.750 \\
\hline $4 a$ & $31(18.7)$ & $6(17.7)$ & \\
\hline $4 \mathrm{~b}$ & $17(10.2)$ & $5(14.7)$ & \\
\hline$>4 \mathrm{c}$ & $118(71.1)$ & $23(67.6)$ & \\
\hline Cancer type & & & 0.021 \\
\hline IDC & $154(92.8)$ & $30(88.2)$ & \\
\hline Mucinous & $9(5.4)$ & $0(0)$ & \\
\hline Medullary & $2(1.2)$ & $3(8.9)$ & \\
\hline Papillary & $1(0.6)$ & $1(2.9)$ & \\
\hline Histologic grade & & & $<0.001$ \\
\hline 1 & $43(26.5)$ & $1(3.0)$ & \\
\hline 2 & $87(53.7)$ & $6(18.2)$ & \\
\hline 3 & $32(19.8)$ & $26(78.8)$ & \\
\hline T-stage & & & 0.027 \\
\hline $\mathrm{T} 1$ & $89(53.6)$ & $12(35.3)$ & \\
\hline $\mathrm{T} 2$ & $68(11.0)$ & $22(64.7)$ & \\
\hline T3 & $9(5.4)$ & $0(0)$ & \\
\hline
\end{tabular}

ated with the highest histologic grade compared to other subtypes in some studies $(30,31)$.

With regard to T stage, HER2-enriched and TN subtypes were both associated with a T-stage of $>2$. HER2-enriched types have been described as involving larger-sized masses and more advanced stages than the other subtypes $(21,31$, $32)$.

In our analyses with two categories of IHC subtypes, we found a significant association between the TN subtype and medullary cancer $(P=0.021)$. Uematsu et al. $(27)$ reported that medullary and metaplastic carcinomas were significantly associated with $\mathrm{TN}$ breast cancer, similar to Cadarella et al.'s (26) report. Leidy et al. (33) also found that
TN subtypes were frequently associated with adenoid cystic carcinoma, apocrine carcinoma, medullary carcinoma and metaplastic carcinoma; all of which have better prognoses than basal-like breast cancer.

Our study only evaluated mammogram and sonogram features; however, several studies have looked at MRI and positron emission tomography/computed tomography (PET/CT) imaging for breast cancer subtypes. Youk et al. (13) reported that TNBC was larger, better defined, and had more necrotic tissue than other cancers, and that necrosis yielded high T2-weighted signal intensity and apparent diffusion coefficient values. Uematsu et al. (27) found similar MR features for TN cancers, including very high intratu- 
Table 3. Multivariate Logistic Regression Analysis of IHC Subtypes for Clinical and Radiologic Factors Compared to the Luminal A Subtype After Adjustment for Histologic Grade

\begin{tabular}{|c|c|c|c|c|c|c|}
\hline \multirow[t]{2}{*}{ Variable } & \multicolumn{2}{|c|}{ Luminal $B(n=54)$} & \multicolumn{2}{|c|}{ HER2 + $(n=35)$} & \multicolumn{2}{|l|}{$\operatorname{TN}(n=34)$} \\
\hline & $\mathrm{OR}(95 \% \mathrm{CI})$ & PValue & OR $(95 \% \mathrm{CI})$ & PValue & $\mathrm{OR}(95 \% \mathrm{CI})$ & P Value \\
\hline Age & $0.981(0.947-1.015)$ & 0.268 & $1.029(0.987-1.072)$ & 0.178 & $0.973(0.9291 .019)$ & 0.245 \\
\hline \multicolumn{7}{|l|}{ Symptoms } \\
\hline No & 1.0 & & 1.0 & & 1.0 & \\
\hline Yes & $0.531(0.255-1.106)$ & 0.091 & $1.099(0.449-2.691)$ & 0.836 & $0.856(0.315-2.323)$ & 0.761 \\
\hline \multicolumn{7}{|l|}{ MMG finding } \\
\hline Negative & 1.0 & & 1.0 & & 1.0 & \\
\hline Asymmetry/mass & $\begin{array}{c}>999.999(<0.001-> \\
999.999)\end{array}$ & 0.951 & $\begin{array}{c}>999.999(<0.001-> \\
999.999)\end{array}$ & 0.962 & $0.364(0.049-2.734)$ & 0.407 \\
\hline $\begin{array}{l}\text { Mass with } \\
\text { calcification }\end{array}$ & $\begin{array}{c}>999.999(<0.001- \\
>999.999)\end{array}$ & 0.948 & $\begin{array}{c}>999.999(<0.001-> \\
999.999)\end{array}$ & 0.958 & $0.285(0.027-2.983)$ & 0.295 \\
\hline
\end{tabular}

US BI-RADS

\begin{tabular}{|c|c|c|c|c|c|c|}
\hline $4 a$ & 1.0 & & 1.0 & & 1.0 & \\
\hline $4 \mathrm{~b}$ & $0.427(0.075-2.417)$ & 0.336 & $9.005(1.414-57.348)$ & 0.020 & $2.027(0.329-12.475)$ & 0.446 \\
\hline$>4 \mathrm{C}$ & $1.284(0.538-3.065)$ & 0.573 & $4.669(0.970-22.468)$ & 0.055 & $1.398(0.402-4.865)$ & 0.598 \\
\hline \multicolumn{7}{|l|}{ Cancer type } \\
\hline IDC & 1.0 & & 1.0 & & 1.0 & \\
\hline Mucinous & $1.200(0.189-7.638)$ & 0.847 & $3.000(0.218-41.351)$ & 0.412 & $<0.001(<0.001->999.999)$ & 0.956 \\
\hline Medullary & $\begin{array}{c}>999.999(<0.001-> \\
999.999)\end{array}$ & 0.970 & $0.515(<0.001->999.999)$ & 0.999 & $<0.001(<0.001->999.999)$ & 0.967 \\
\hline Papillary & $<0.001(<0.001->999.999)$ & 0.978 & $<0.001(<0.001->999.999)$ & 0.982 & $<0.001(<0.001->999.999)$ & 0.984 \\
\hline \multicolumn{7}{|l|}{ T-stage } \\
\hline $\mathrm{T} 1$ & 1.0 & & 1.0 & & 1.0 & \\
\hline $\mathrm{T} 2$ & $1.226(0.579-2.597)$ & 0.595 & $3.173(1.248-8.066)$ & 0.015 & $2.376(0.876-6.446)$ & 0.089 \\
\hline T3 & $0.469(0.046-4.783)$ & 0.523 & $6.552(1.252-34.296)$ & 0.026 & $<0.001(<0.001->999.999)$ & 0.989 \\
\hline
\end{tabular}

Abbreviations: BI-RADS, breast imaging reporting and data system; IDC, invasive ductal carcinoma; MMG, mammographic; TN, triple negative; US, ultrasound; OR, odds ratio; HER2, human epidermal growth factor receptor 2; CI, confidence interval; IHC, immunohistochemical.

moral signal intensity on T2-weighted MR imaging and intratumoral necrosis. Bae et al. (19) reported that androgenreceptor-positive TN cancers were more likely to be associated with non-mass types and a higher incidence of irregular and spiculated lesions on MRI than androgen-receptornegative TN cancers. Koo et al. (34) found that $18 \mathrm{~F}$ fluorodeoxyglucose (FDG) PET showed higher FDG uptake in the TN subtype (1.67-fold) and the HER2 subtype (1.27-fold) than in the luminal A type.

As prior studies have reported, TN subtype cancers display well-defined benign masses on mammography and US, as well as a higher necrotic portion and rim-enhanced lesions on MRI, and advanced T-staging and histologic grade (13). Another study (35) reported that TNBC was associated with younger age; however, in this study, we found no significant differences associated with age.
The present study has several limitations. First, it is retrospective and therefore may be affected by selection bias, so only excised cases and known IHC profiles were included. Second, the sample size $(n=200)$ was fairly small, and to draw clearer conclusions, another study with a larger sample size and a prospective design will be necessary. Third, this study evaluated the mammographic and sonographic features of breast cancer according to the IHC subtypes. However, MRI and other modalities would also be useful to study.

In conclusion, TNBC exhibited well-defined, benign masses on mammography and US, and was significantly associated with medullary cancer. Higher histologic grade and higher T-stage were typically seen among TNBC cases, as shown by HER2-enriched subtypes. 
Table 4. Multivariate Logistic Regression Analysis of TN Subtype for Clinical and Radiologic Factors Compared to non-TN Subtypes After Adjusting for Histologic Grade

\begin{tabular}{|c|c|c|}
\hline \multirow[t]{2}{*}{ Variable } & \multicolumn{2}{|c|}{$\operatorname{TN}(\mathbf{n}=\mathbf{3 4})$} \\
\hline & OR $(95 \% \mathrm{CI})$ & PValue \\
\hline Age & $0.970(0.931-1.011)$ & 0.149 \\
\hline \multicolumn{3}{|l|}{ Symptoms } \\
\hline No & 1.0 & \\
\hline \multicolumn{3}{|l|}{ MMG finding } \\
\hline Negative & 1.0 & \\
\hline Asymmetry/mass & $0.173(0.025-1.192)$ & 0.075 \\
\hline Mass with microcalcification & $0.246(0.045-1.345)$ & 0.106 \\
\hline \multicolumn{3}{|l|}{ US BI-RADS } \\
\hline $4 a$ & 1.0 & \\
\hline $4 \mathrm{~b}$ & $1.520(0.403-5.723)$ & 0.536 \\
\hline$>4 \mathrm{c}$ & $1.007(0.377-2.688)$ & 0.989 \\
\hline \multicolumn{3}{|l|}{ Cancer type } \\
\hline IDC & 1.0 & \\
\hline Mucinous & $0.267(0.013-5.479)$ & 0.391 \\
\hline Medullary & $7.092(1.149-43.772)$ & 0.035 \\
\hline Papillary & $5.061(0.308-83.153)$ & 0.256 \\
\hline \multicolumn{3}{|l|}{ T-stage } \\
\hline $\mathrm{T} 1$ & 1.0 & \\
\hline $\mathrm{T} 2$ & $2.155(0.345-13.444)$ & 0.411 \\
\hline
\end{tabular}

Abbreviations: BI-RADS, breast imaging reporting and data system; IDC, invasive ductal carcinoma; MMG, mammographic; TN, triple negative; US, ultrasound; OR, odds ratio; $\mathrm{CI}$, confidence interval; IHC, immunohistochemical.

\section{Footnotes}

Authors' Contributions: Yu-Mee Sohn: design and writing of entire manuscript; Kyunghwa Han: statistical analysis; Mirinae Seo: manuscript proofreading.

Financial Disclosures: None declared.

Funding/Support: None declared.

\section{References}

1. de Ronde JI, Hannemann J, Halfwerk H, Mulder L, Straver ME, Vrancken Peeters MJ, et al. Concordance of clinical and molecular breast cancer subtyping in the context of preoperative chemotherapy response. Breast Cancer Res Treat. 2010;119(1):11926. doi: 10.1007/s10549-009-0499-6. [PubMed: 19669409].

2. Sorlie T, Perou CM, Tibshirani R, Aas T, Geisler S, Johnsen H, et al. Gene expression patterns of breast carcinomas distinguish tumor subclasses with clinical implications. Proc Natl Acad Sci U S A. 2001;98(19):10869-74. doi: 10.1073/pnas.191367098. [PubMed: 11553815].
3. Yamamoto $\mathrm{Y}$, Iwase $\mathrm{H}$. Clinicopathological features and treatment strategy for triple-negative breast cancer. Int J Clin Oncol. 2010;15(4):341-51. doi: 10.1007/s10147-010-0106-1. [PubMed: 20632057].

4. Goldhirsch A, Wood WC, Coates AS, Gelber RD, Thurlimann B, Senn $\mathrm{HJ}$, et al. Strategies for subtypes-dealing with the diversity of breast cancer: highlights of the St. Gallen International Expert Consensus on the Primary Therapy of Early Breast Cancer 2011. Ann Oncol. 2011;22(8):1736-47. doi: 10.1093/annonc/mdr304. [PubMed: 21709140].

5. Perou CM, Sorlie T, Eisen MB, van de Rijn M, Jeffrey SS, Rees $\mathrm{CA}$, et al. Molecular portraits of human breast tumours. Nature. 2000;406(6797):747-52. doi: 10.1038/35021093. [PubMed: 10963602].

6. Montagna E, Bagnardi V, Rotmensz N, Viale G, Cancello G, Mazza M, et al. Immunohistochemically defined subtypes and outcome in occult breast carcinoma with axillary presentation. Breast Cancer Res Treat. 2011;129(3):867-75. doi: 10.1007/s10549-011-1697-6. [PubMed: 21822638].

7. Carey LA, Perou CM, Livasy CA, Dressler LG, Cowan D, Conway K, et al. Race, breast cancer subtypes, and survival in the Carolina Breast Cancer Study.JAMA. 2006;295(21):2492-502. doi:10.1001/jama.295.21.2492. [PubMed: 16757721].

8. Bae MS, Moon WK, Chang JM, Cho N, Park SY, Won JK, et al. Mammographic features of calcifications in DCIS: correlation with oestrogen receptor and human epidermal growth factor receptor 2 status. Eur Radiol. 2013;23(8):2072-8. doi: 10.1007/s00330-013-2827-9. [PubMed: 23512196]. 
9. Ko ES, Lee BH, Kim HA, Noh WC, Kim MS, Lee SA. Triple-negative breast cancer: correlation between imaging and pathological findings. Eur Radiol. 2010;20(5):1111-7. doi: 10.1007/s00330-009-1656-3. [PubMed: 19898850].

10. Kojima Y, Tsunoda H. Mammography and ultrasound features of triple-negative breast cancer. Breast Cancer. 2011;18(3):146-51. doi: 10.1007/s12282-010-0223-8. [PubMed: 20972742].

11. Kojima Y, Tsunoda H, Honda S, Kikuchi M, Kawauchi N, Yoshida A, et al. Radiographic features for triple negative ductal carcinoma in situ of the breast. Breast Cancer. 2011;18(3):213-20. doi: 10.1007/s12282-0110261-x. [PubMed: 21465228].

12. Youk JH, Gweon HM, Son EJ, Kim JA, Jeong J. Shear-wave elastography of invasive breast cancer: correlation between quantitative mean elasticity value and immunohistochemical profile. Breast Cancer Res Treat. 2013;138(1):119-26. doi: 10.1007/s10549-013-2407-3. [PubMed: 23324903].

13. Youk JH, Son EJ, Chung J, Kim JA, Kim EK. Triple-negative invasive breast cancer on dynamic contrast-enhanced and diffusion-weighted MR imaging: comparison with other breast cancer subtypes. Eur Radiol. 2012;22(8):1724-34.

14. American College of Radiology . Breast imaging reporting and data system(BI-RADS) mammography. 5 ed. USA: American College of Radiology; 2013.

15. American College of Radiology . Breast imaging reporting and data system(BI-RADS) ultrasound. 5 ed. USA: American College of Radiology; 2013.

16. Edge SB, Byrd DR CCC. AJCC cancer staging manual. 7 ed. New York: Springer; 2010.

17. Wolff AC, Hammond ME, Schwartz JN, Hagerty KL, Allred DC, Cote RJ. American Society of Clinical Oncology/College of American Pathologists guideline recommendations for human epidermal growth factor receptor 2 testing in breast cancer. J Clin Oncol. 2007;25(1):118-45.

18. Bloom HJ, Richardson WW. Histological grading and prognosis in breast cancer; a study of 1409 cases of which 359 have been followed for 15 years. BrJ Cancer. 1957;11(3):359-77. [PubMed: 13499785].

19. Bae MS, Park SY, Song SE, Kim WH, Lee SH, Han W. Heterogeneity of triple-negative breast cancer: mammographic, US, and MR imaging features according to androgen receptor expression. Eur Radiol. 2014.

20. Bae MS, Seo M, Kim KG, Park IA, Moon WK. Quantitative MRI morphology of invasive breast cancer: correlation with immunohistochemical biomarkers and subtypes. Acta Radiol. 2015;56(3):269-75. doi: 10.1177/0284185114524197. [PubMed: 24558165].

21. Kim SH, Seo BK, Lee J, Kim SJ, Cho KR, Lee KY, et al. Correlation of ultrasound findings with histology, tumor grade, and biological markers in breast cancer. Acta Oncol. 2008;47(8):1531-8. doi: 10.1080/02841860801971413. [PubMed: 18607848]

22. Seo BK, Pisano ED, Kuzimak CM, Koomen M, Pavic D, Lee Y, et al. Correlation of HER-2/neu overexpression with mammography and age distribution in primary breast carcinomas. Acad Radiol. 2006;13(10):12118. doi:10.1016/j.acra.2006.06.015. [PubMed: 16979070].

23. Yang WT, Dryden M, Broglio K, Gilcrease M, Dawood S, Dempsey PJ, et al. Mammographic features of triple receptor-negative primary breast cancers in young premenopausal women. Breast Cancer Res Treat. 2008;111(3):405-10. doi: 10.1007/s10549-007-9810-6. [PubMed: 18026834].

24. Dogan BE, Gonzalez-Angulo AM, Gilcrease M, Dryden MJ, Yang WT. Multimodality imaging of triple receptor-negative tumors with mammography, ultrasound, and MRI. AJR Am J Roentgenol. 2010;194(4):1160-6. doi: 10.2214/AJR.09.2355. [PubMed: 20308526].

25. Choi YJ, Seong MH, Choi SH, Kook SH, Kwag HJ, Park YL. Ultrasound and clinicopathological characteristics of triple receptor-negative breast cancers. J Breast Cancer. 2011;14(2):119-23.

26. Caldarella A, Buzzoni C, Crocetti E, Bianchi S, Vezzosi V, Apicella $\mathrm{P}$, et al. Invasive breast cancer: a significant correlation between histological types and molecular subgroups. J Cancer Res Clin Oncol. 2013;139(4):617-23. doi: 10.1007/s00432-012-1365-1. [PubMed: 23269487].

27. Uematsu T, Kasami M, Yuen S. Triple-negative breast cancer: correlation between MR imaging and pathologic findings. Radiol. 2009;250(3):638-47.

28. Boisserie-Lacroix M, Mac Grogan G, Debled M, Ferron S, Asad-Syed $\mathrm{M}$, Brouste $\mathrm{V}$, et al. Radiological features of triple-negative breast cancers (73 cases). Diagn Interv Imaging. 2012;93(3):183-90. doi: 10.1016/j.diii.2012.01.006. [PubMed: 22421282].

29. Krizmanich-Conniff KM, Paramagul C, Patterson SK, Helvie MA Roubidoux MA, Myles JD, et al. Triple receptor-negative breast cancer: imaging and clinical characteristics. AJR Am I Roentgenol. 2012;199(2):458-64. doi: 10.2214/AJR.10.6096. [PubMed: 22826413].

30. Wang X, Chao L, Chen L, Ma G, Jin G, Hua M, et al. The mammographic correlations with Basal-like phenotype of invasive breast cancer. Acad Radiol. 2010;17(3):333-9. doi: 10.1016/j.acra.2009.10.011. [PubMed: 19962918].

31. Tamimi RM, Baer HJ, Marotti J, Galan M, Galaburda L, Fu Y, et al. Comparison of molecular phenotypes of ductal carcinoma in situ and invasive breast cancer. Breast Cancer Res. 2008;10(4):R67. doi: 10.1186/bcr2128. [PubMed: 18681955].

32. Wang Y, Ikeda DM, Narasimhan B, Longacre TA, Bleicher RJ, Pal S, et al. Estrogen receptor-negative invasive breast cancer: imaging features of tumors with and without human epidermal growth factor receptor type 2 overexpression. Radiology. 2008;246(2):367-75. doi: 10.1148/radiol.2462070169. [PubMed: 18180338].

33. Leidy J, Khan A, Kandil D. Basal-like breast cancer: update on clinicopathologic, immunohistochemical, and molecular features. Arch Pathol Lab Med. 2014;138(1):37-43. doi: 10.5858/arpa.2012-0439-RA. [PubMed: 24377810].

34. Koo HR, Park JS, Kang KW, Cho N, Chang JM, Bae MS, et al. 18F-FDG uptake in breast cancer correlates with immunohistochemically defined subtypes. Eur Radiol. 2014;24(3):610-8. doi: 10.1007/s00330-0133037-1. [PubMed: 24097303].

35. Wojcinski S, Soliman AA, Schmidt J, Makowski L, Degenhardt F, Hillemanns P. Sonographic features of triple-negative and non-triplenegative breast cancer. JUltrasound Med. 2012;31(10):1531-41. [PubMed: 23011616]. 